\title{
Detection of latent fingermarks on thermal printer paper by dry contact with 1,2-indanedione
}

\author{
Emma L.T. Patton, David H. Brown and Simon W. Lewis ${ }^{a}$ \\ Received (in $X X X, X X X) X$ th $X X X X X X X X X 200 X$, Accepted Xth $X X X X X X X X X 200 X$ \\ ${ }_{5}$ First published on the web Xth $X X X X X X X X X 200 X$ \\ DOI: $10.1039 / b 000000 x$
}

A new method for the detection of latent fingermarks on thermal paper by dry contact with 1,2indanedione, which reacts with the amino acids present to give coloured, photoluminescent prints is described. The simple and reliable method is based on contact between the thermal paper sample 10 and reagent impregnated treatment papers. Different treatment paper reagent formulations and treatment times were investigated. The conditions which provided the best performance used treatment papers prepared from an acid-free fluorous solution containing 1,2-indanedione and zinc chloride, with a contact time of $48 \mathrm{hrs}$. The dry contact approach was compared to current methods used by law enforcement agencies within Australia and was found to give similar or better

15 performance.

Key words: latent fingermarks, fingerprint, 1,2-indanedione, thermal paper, dry contact

\section{Introduction}

The impressions left by the ridge skin present on the grasping surfaces of the hands are extremely important in establishing 20 contact and personal identification in criminal investigations. $^{1,2}$ Latent fingermarks, primarily composed of skin secretions (e.g. sweat), are invisible to the naked eye and thus require a development process to be visualised. ${ }^{1-4}$ The principle approach for revealing latent fingermarks on porous 25 surfaces (e.g. paper or cardboard) is chemical development with amino acid sensitive reagents. ${ }^{5}$ This is essentially the trace detection of the amino acids present in skin secretions that have been deposited on a surface, where the position of the analyte within the matrix is important. Widely used 30 reagents for this purpose include ninhydrin, 1,8-diazafluoren9-one (DFO) or 1,2-indanedione (IND) (Figure 1), to form coloured products. DFO and IND have been termed "dual reagents" as their reaction products are both coloured and photoluminescent. ${ }^{6}$ Dual reagents afford greater detection 35 sensitivity and contrast due to their photoluminescent properties. $^{5,6}$
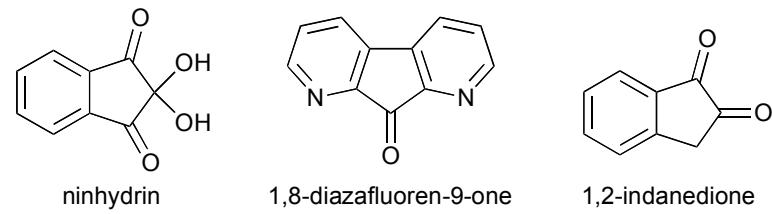

Fig.1 Chemical structures of amino acid sensitive reagents for the detection of latent fingermarks on porous surfaces.

40 Thermal paper is a heat sensitive paper most commonly used for sales receipts and fax papers, and can be of interest in cases of fraud and identity theft. It is different to most porous surfaces that are encountered by fingerprint examiners in that it is made up of several layers, each with a functional ${ }_{45}$ purpose. $^{7}$ The most important layers are the active coat, which contains the chemicals for the printed image, and the top and back coats that seal the paper on which latent fingermarks may be deposited. ${ }^{7}$

Since its introduction, thermal paper has presented a 50 challenge when using amino acid sensitive reagents to detect latent fingermarks. Samples are dipped into an organic solution containing the reagent (e.g ninhydrin, IND), and depending on the procedure, additional components such as acid or metal salts. ${ }^{5,8}$ After being air dried the sample may 55 then be exposed to heat and/or humidity to develop the fingermarks as coloured impressions. Organic solvents, particularly polar solvents, react with the chemicals in the active coat of thermal paper causing irreversible damage to the sample and can obscure any printed text or developed 60 fingermarks. ${ }^{7,9,10}$ Additionally, the heating step commonly used in latent fingermark development also results in discolouration of the paper.

Alternative methods have been proposed to overcome these problems. These include modification of a ninhydrin ${ }_{65}$ formulation to use a less polar solvent, ${ }^{7}$ or the preparation of ninhydrin derivatives such as ninhydrin hemiketals, that minimise the concentration of polar solvents required for dissolution of the reagent. ${ }^{9,11}$ Other methods have focused on whitening the background using cellophane/sticky tape (after 70 a ninhydrin-based treatment), ${ }^{12}$ or washing with acetone or solutions containing nitrogenous organic compounds (after treatments with either ninhydrin or DFO). ${ }^{9}$

Approaches which eliminate the requirement for a solvent have also been investigated. Treating samples by fuming with 75 ninhydrin $^{13}$ or reagents such as dimethylaminocinnamaldehyde (DMAC), ${ }^{14}$ iodine, ${ }^{15}$ hydrochloric acid, ${ }^{16}$ acetic acid, ${ }^{10}$ and steam $^{17}$ have been reported. There has also been some research into the use of vacuum metal deposition ${ }^{17}$ and controlled heating ${ }^{18}$ as 80 methods for latent fingermark development.

Methods based on direct contact between thermal paper and 
paper impregnated with reagent have been reported using ninhydrin and DMAC. ${ }^{19-21}$ One technique, that has been termed 'Nin-dry', involves placing the sample between two pieces of dry ninhydrin-impregnated paper for a number of 5 days in a sealed plastic bag. ${ }^{20,21}$ This method requires no heat treatment and can afford good development of latent fingermarks with minimal damage to the document. ${ }^{21}$ The DMAC contact method for thermal paper uses reagent impregnated sheets placed in a press for 24 hours. ${ }^{19}$ This

10 process developed fingermarks that were luminescent and left the printed text intact, but was deemed not as effective as treatment with DFO or ninhydrin. ${ }^{19}$

Of the aforementioned methods, only a few can produce photoluminescent fingermarks, primarily those treating with 15 DFO solutions ${ }^{9,19}$ and the DMAC contact method. ${ }^{19}$ There has been little investigation into the more recently introduced reagent 1,2-indanedione (IND), with only two reported methods for the treatment of thermal papers, ${ }^{22,23}$ both of which use wet, dipping treatments. The most recent method, 20 recommended by the Australian Federal Police (AFP), involves dipping thermal paper samples into an acid-free IND and zinc chloride solution and then drying with no subsequent heat treatment. ${ }^{23}$

Here we present an investigation into a simple technique 25 for the development of latent fingermarks on thermal papers using a dry contact method based on 1,2-indanedione, that produces photoluminescent fingermarks.

\section{Materials and Methods}

\section{Chemicals}

30 1,2-Indanedione (CASALI/Optimum Technology, Australia), anhydrous zinc chloride (BDH), dichloromethane (Mallingckrodt chemicals), ethyl acetate (Univar analytical, Australia), glacial acetic acid (CSR chemicals, Australia), absolute ethanol (CSR chemicals, Australia), HFE-7100 ${ }^{\mathrm{TM}}$ (135 methoxynonafluorobutane, $3 \mathrm{M}$ Novec, Australia) and Petroleum spirit $60-80^{\circ} \mathrm{C}$ (APS chemicals, Australia) were used as received and were all analytical grade unless stated otherwise.

\section{Preparation of reagent solutions and treatment papers}

40 Reagent solutions containing 1,2-indandione and zinc chloride were prepared as recommended by the Australian Federal Police (AFP). ${ }^{23}$ The two primary stock solutions were IND/ $\mathbf{Z n C l}_{\mathbf{2}}$ (0.5 g 1,2-indanedione, $20 \mathrm{mg} \mathrm{ZnCl}_{2}, 5 \mathrm{~mL}$ acetic acid, $0.5 \mathrm{~mL}$ ethanol, $15 \mathrm{~mL}$ dichloromethane and $30 \mathrm{~mL}$ 45 ethyl acetate) and acid-free/ $\mathbf{I N D} / \mathbf{Z n C l}_{2} \quad\left(\begin{array}{llll}0.75 & \mathrm{~g} & 1,2-\end{array}\right.$ indanedione, $20 \mathrm{mg} \mathrm{ZnCl}, \quad 0.5 \mathrm{~mL}$ ethanol, $15 \mathrm{~mL}$ dichloromethane and $35 \mathrm{~mL}$ ethyl acetate). Working solutions were prepared by dilution of the stock solution with either HFE-7100 or petroleum spirits, as per Table 1 .

${ }_{50}$ Four different dry contact treatment papers were prepared by dipping chromatography paper (Whatman No.1) in one of the four working solutions (Table 1) and allowed to air dry. These papers were used within 24 hours of preparation. For convenience we will refer to the treatment papers based on the ${ }_{55}$ working solutions used to prepare them.
Table 1 Composition of working solutions.

\begin{tabular}{ccc}
\hline Working solution & Stock solution & Diluent \\
\hline Fluorous IND/ZnCl & $5 \mathrm{~mL}$ IND/ZnCl & $45 \mathrm{~mL}$ HFE-7100 \\
Non-fluorous IND/ZnCl & $5 \mathrm{~mL} \mathbf{I N D} / \mathbf{Z n C l}_{\mathbf{2}}$ & $45 \mathrm{~mL}$ Pet. spirits \\
$\begin{array}{c}\text { Fluorous acid- } \\
\text { free/IND/ZnCl }\end{array}$ & $5 \mathrm{~mL}$ acid-free/IND/ZnCl & $45 \mathrm{~mL} \mathrm{HFE-7100}$ \\
$\begin{array}{c}\text { Non-fluorous acid- } \\
\text { free/IND/ZnCl }\end{array}$ & $5 \mathrm{~mL}$ acid-free/IND/ZnCl & $45 \mathrm{~mL}$ Pet. spirits \\
\hline
\end{tabular}

\section{Collection of latent fingermark samples}

Latent fingermark impressions were taken from a single donor, unless otherwise stated. When replicate latent ${ }_{60}$ impressions were required from a single donor, they were collected periodically over a 7 hour period, except for the depletion series. Donors were asked not to wash their hands immediately before collecting impressions, or to 'charge' their fingers by rubbing their fingers on their faces or hair. The ${ }_{65}$ donors were asked to rub their hands together prior to deposition of latent fingermarks and to touch the paper lightly. Latent fingermark samples were treated between 1 and 7 days after collection.

For the initial investigations, whole latent fingermarks were 70 collected on unprinted Thermal Register Rolls (Officeworks, Australia) and printed receipts from a number of supermarkets. These samples were then divided in two, and each half was developed with a different method. Investigations into dipping and air drying development 75 methods were carried out on whole latent fingermarks. For investigations into the use of treatment papers in dry contact mode, whole latent fingermarks were collected on unprinted Thermal Register Rolls (Officeworks, Australia) and printed receipts. These fingermarks were then divided into quarters 80 and each quarter was developed with a different treatment paper, or for a different length of time.

\section{Development of thermal paper samples using wet methods}

Samples developed by dipping and heat treatment were dipped into a working solution, allowed to air dry, then heat ${ }_{85}$ treated in an Elna laundry press (initial experiments: ca. 160 ${ }^{\circ} \mathrm{C}, 10 \mathrm{~s}$; later experiments: ca. $50{ }^{\circ} \mathrm{C}, 5 \mathrm{~s}$ ). Samples developed by dipping without heat treatment were dipped into a working solution and then left in the fume cupboard until dry. These two methods represent the AFP methods for non90 thermal and thermal papers respectively.

Development of thermal paper samples using the dry contact method

Development of samples by the dry contact method using prepared treatment papers involved placing a sample between 95 two pieces of dry treatment paper, sealing in a plastic zip-lock bag and leaving in the dark, unweighted, for a specific period of time. Samples were removed from the bag and photographed in absorbance and luminescence modes at $24 \mathrm{~h}$ intervals for up to $96 \mathrm{~h}$ unless otherwise stated. 


\section{Testing the dry contact method for normal paper}

Depletion series ${ }^{24}$ on white photocopy paper (FUJI Xerox Professional, Australia) were collected from one male and one female donor. The depletion series were halved and one half 5 was developed using the AFP method for non-thermal paper (dipping in fluorous $\mathbf{I N D} / \mathbf{Z n C l}_{\mathbf{2}}$ working solution followed by heat treatment) and the other half was developed with a modified dry contact method (the sample was placed between fluorous $\mathbf{I N D} / \mathbf{Z n C l}_{\mathbf{2}}$ treatment papers and subjected to $c a$. $10160{ }^{\circ} \mathrm{C}$ for $10 \mathrm{~s}$ in an Elna laundry press).

\section{Comparison of the dry contact method to other development methods}

A blind trial comparison was conducted, using four fingermark donors ( 3 male and 1 female). Over the course of 6 15 hours the donors deposited a number of prints randomly across 20 unprinted thermal paper samples using varying amounts of pressure. A list of number and position of the deposits on each piece of paper was recorded and remained unsighted by the analyst until the samples had been developed 20 and analysed. One set of 10 thermal paper samples were developed using the AFP method for thermal paper (dipping in fluorous acid-free/IND/ $\mathbf{Z n C l}_{\mathbf{2}}$ working solution followed by air drying and no heat treatment); and the other set using the dry contact method described in this paper (using fluorous

${ }_{25}$ acid-free/IND/ $\mathbf{Z n C l}_{2}$ treatment papers), with a $48 \mathrm{~h}$ development time.

For a direct comparison between the various development methods, latent fingermarks from two donors on unprinted thermal paper samples were cut into quarters and treated with 30 one of four visualisation methods: (i) the AFP method for non-thermal papers (dipping in fluorous $\mathbf{I N D} / \mathbf{Z n C l}_{\mathbf{2}}$ working solution followed by heat treatment); (ii) the AFP method for thermal paper (dipping in fluorous acid-free/IND/ $\mathbf{Z n C l}_{2}$ working solution followed by air drying and no heat 35 treatment); (iii) the dry contact method described in this paper (using fluorous acid-free/IND/ $\mathbf{Z n C l}_{\mathbf{2}}$ treatment papers); and (iv) a dry contact method using ninhydrin impregnated treatment papers (the 'Nin-dry' method), used by the Western Australian Police (WAPOL). The 'Nin-dry' method is as 40 follows: a ninhydrin solution was prepared as detailed in the AFP workshop manual ${ }^{23}$ and sprayed onto white photocopy paper (Green Wrap, Fuji Xerox, Australia) which was allowed to air dry. Samples were then placed between 'Nin-dry' treatment papers in a zip-lock plastic bag in a dark cupboard,

45 unweighted. Samples were checked for fingermark development at 24,48 and $72 \mathrm{~h}$.

\section{Photography of Samples}

Samples were photographed in both absorbance (white-light) mode and luminescence mode using a Nikon D100 or D300 ${ }_{50}$ digital cameras. Illumination in absorbance mode was achieved using incandescent light bulbs with no camera filter attachments. Illumination in luminescence mode was achieved using a Rofin Polilight ${ }^{\circledR}$ PL500 (Rofin, Australia), with an excitation wavelength of $505 \mathrm{~nm}$ and an orange camera filter 55 attachment (550 nm barrier filter). The camera settings for all photographs were as shown in Table 2 .
Table 2 Photographic conditions for absorbance and luminescence mode photographs, unless otherwise stated.

\begin{tabular}{ccc}
\hline & Absorbance mode & Luminescence mode \\
\hline Focal Length (mm) & 60 & 85 \\
Exposure Mode & Manual & Manual \\
White Balance & Auto & Auto \\
Shutter Speed (s) & $1 / 25$ & 4 \\
Aperture & $\mathrm{f} / 11$ & $\mathrm{f} / 11$ \\
Sensitivity & ISO 200 & ISO 200 \\
\hline
\end{tabular}

Visual analysis of developed fingermarks

${ }_{60}$ In this study, a system based on that used by the Home Office Police Scientific Development Branch (HOPSDB) UK, ${ }^{24}$ consisting of four levels was used to grade the development of fingermarks (Table 3 ).

Table 3 Latent fingermark development grading system used in this 65 study.

\begin{tabular}{|c|c|c|}
\hline \multicolumn{2}{|r|}{ Grade } & Description \\
\hline 0 & No development & $\begin{array}{c}\text { No visible ridge detail in colour or } \\
\text { luminescence }\end{array}$ \\
\hline 1 & Weak development & $\begin{array}{l}\text { Patchy ridge detail development with less } \\
\text { visible colour or luminescence }\end{array}$ \\
\hline 2 & Medium development & $\begin{array}{l}\text { Mostly continuous ridge detail development } \\
\text { with visible colour or luminescence }\end{array}$ \\
\hline 3 & Strong development & $\begin{array}{l}\text { Continuous ridge detail development with } \\
\text { readily visible colour or luminescence }\end{array}$ \\
\hline
\end{tabular}

\section{Results and Discussion}

\section{Preliminary considerations}

Fingermarks are not absolutely reproducible and so it is important to establish a system of assessing the quality of 70 developed fingermarks that takes into account their variable nature. Variability in the quality of developed fingermarks can arise due to: different skin secretion compositions, the presence of contaminants on the hands; and variation in the pressure applied when leaving the deposit.

75 Two complementary methods can be used to directly compare the performance of fingermark development reagents. These are the 'split print' and depletion series approaches. The 'split print' approach is where a single latent fingermark is divided into two or more sections, so that each 80 section can be treated differently. The depletion series approach is where a series of latent fingermarks are deposited one after the other, without the donors fingers touching anything between each deposition, so as to give a series of prints that have decreasing amounts of deposited material. ${ }^{24,25}$ ${ }_{85}$ Both approaches have been used in this study.

\section{Method of applying development reagents}

Preliminary experiments were carried out to determine whether 1,2-indanedione would develop latent fingermarks on thermal paper through a dry contact process. Latent 90 fingermarks were deposited on thermal paper which was placed between sheets of 1,2-indanedione impregnated paper and sealing in a plastic zip-lock bag and left overnight in the dark. Coloured, photoluminescent fingermarks were successfully developed with all samples. 
Following these successful preliminary studies the dry contact method was compared to other approaches for application of 1,2-indanedione/zinc chloride including dipping and heating (as per the AFP recommendations for non-thermal ${ }_{5}$ papers ${ }^{23}$ ), and dipping and air drying (as per the AFP recommendations for thermal paper ${ }^{23}$ ). The techniques recommended by the AFP are widely used throughout law enforcement in Australia as standard methods for the development of latent fingermarks.

10 Initial investigations into the different methods of applying 1,2-indanedione/zinc chloride reagents focused on the comparison between the dry contact method (using fluorous IND $/ \mathbf{Z n C l}_{2}$ treatment papers) and the AFP method for nonthermal papers (dipping in fluorous $\mathbf{I N D} / \mathbf{Z n C l}_{\mathbf{2}}$ working 15 solution and subsequent heat treatment). These experiments showed that when a thermal paper sample, printed or unprinted, is dipped and heated at ca. $160{ }^{\circ} \mathrm{C}$ significant blackening of the background occurs obscuring both latent fingermarks and printed evidence. However, the dry contact 20 treatment developed fingermarks that were visible in absorbance and photoluminescence imaging modes (Figure 2). Decreasing the heating to $\mathrm{ca} .50^{\circ} \mathrm{C}$ for 5 seconds still resulted in discolouration of the background.
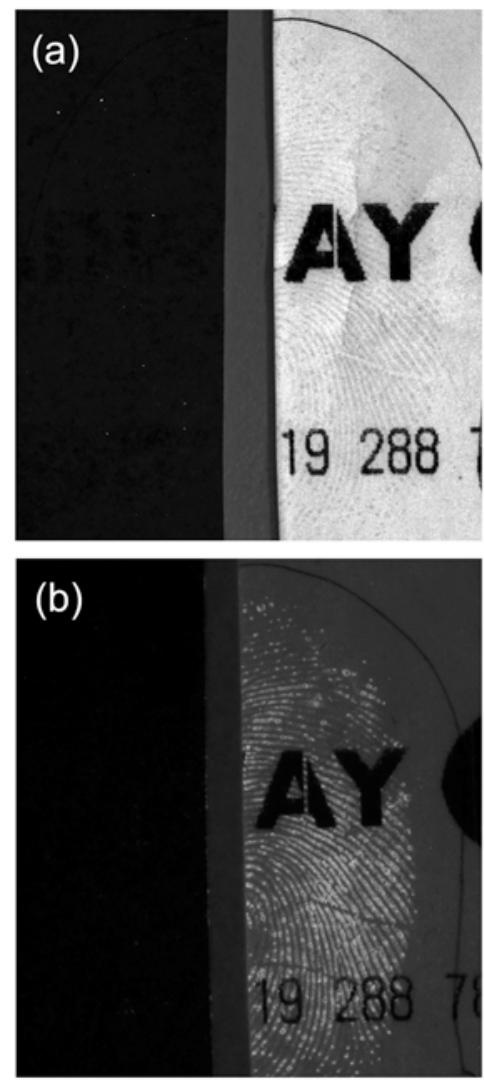

25 Fig.2 Latent fingermarks on printed thermal paper, where halves were treated with fluorous IND/ZnCl 2 using (on the left) the AFP method for non-thermal papers (dipping with heating) or (on the right) the dry contact method. Photographs taken with a Nikon D300 Camera in (a) absorbance mode or (b) luminescence mode with settings; Focal length: $60 \mathrm{~mm}$, Shutter Speed: $2.5 \mathrm{~s}$ and Aperture: f/14.
When samples were dipped into working solutions and air dried, without heat treatment, discolouration also occurred. The extent of this varied depending on the time the sample 35 was left in solution and the formulation of the development solution. In terms of discolouration of the thermal paper, the non-fluorous solutions (petroleum spirits based) were more detrimental than fluorous development solutions (HFE-7100 based). This was also the case with solutions containing acid. 40 It is important to note that the discolouration caused by dipping without heating was significantly less than when the samples were dipped and heated.

In comparison the thermal paper samples developed by the dry contact method developed slowly but without any ${ }_{45}$ darkening of the background.

Investigations into reagent formulation for dry contact treatment papers

Since acidic components of development solutions had a detrimental effect on the active layer of thermal paper in the 50 wet dipping methods, it was postulated that residual acid in the treatment papers may also be problematic. Working solutions, used to prepare treatment papers, containing no acid were investigated (e.g. fluorous acid-free/IND/ZnCl $\mathbf{n}_{\mathbf{2}}$, Table 1). While the AFP recommend the use of the fluorous solvent ${ }_{55}$ HFE-7100 for development solutions, petroleum spirits was also investigated as it is a less expensive alternative to $\mathrm{HFE}$ 7100 .

On samples of unprinted thermal paper, fingermark quarters developed using treatment papers prepared from acetic acid${ }_{60}$ containing working solutions (fluorous $\mathbf{I N D} / \mathbf{Z n C l}_{2}$ and nonfluorous $\mathbf{I N D} / \mathbf{Z} \mathbf{n C l}_{\mathbf{2}}$ ) often showed a more intense colour and luminescence than those without acid (fluorous acidfree/IND/ZnCl 2 and non-fluorous acid-free/IND/ $\mathrm{ZnCl}_{2}$ ). However, the development was patchy and uneven across the 65 quarter, and in some cases there was no development at all, averaging a development grade from 0-1 (as per Table 3). While the fingermarks developed using treatment papers prepared from solutions containing no acid (fluorous acidfree/IND/ZnCl $\mathbf{Z n}_{\mathbf{2}}$ and non-fluorous acid-free/IND/ZnCl $\mathbf{Z n}_{2}$ ) 70 often had less intense colour and luminescence, there was more consistent development of the ridge patterns of the fingermark, with an average grade from 2-3 (see Figure 3). These results indicate that the inclusion of acid in visualisation solutions does have a detrimental effect on

75 fingermark development on thermal paper. There was no notable difference in development of fingermarks between treatment papers prepared from fluorous or non-fluorous working solutions.

On printed thermal paper samples similar observations 80 were made. Fingermark quarters developed with fluorous acid-free/IND/ $\mathbf{Z n C l}_{2}$-based treatment papers often demonstrated brighter luminescence than quarters developed with the other treatment papers. Of the four different working solutions investigated, the treatment papers prepared with ${ }_{85}$ fluorous acid-free/IND/ $\mathbf{Z n C l}_{2}$ (Table 1) generally developed more fingermark quarters of greater quality (grade 2 and 3) than the treatment papers prepared with the other working solutions. It was also found that petroleum spirit was a 
suitable replacement for HFE-7100, however, the quality of the developed fingermark is decreased. It should be noted that when the printed text overlapped the fingermarks, the ridge detail was obscured in both absorbance and luminescence 5 mode.

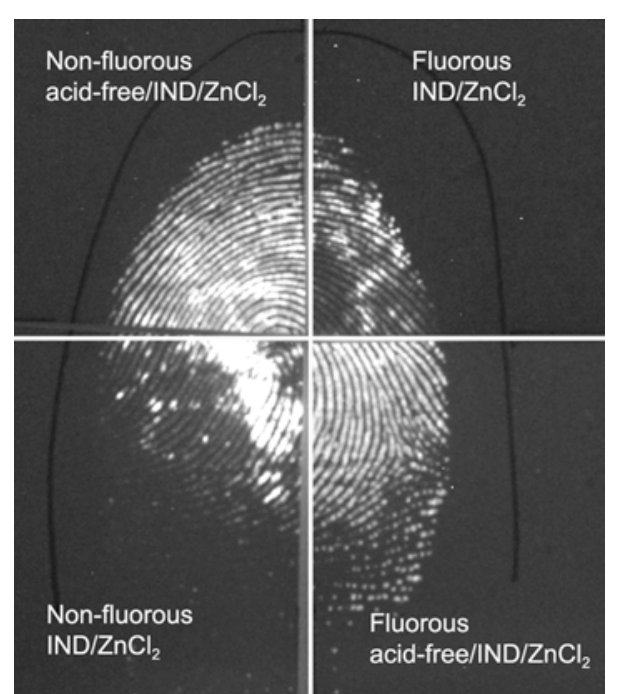

Fig.3 Latent fingermark on unprinted thermal paper where quarters were treated with visualisation solutions using the dry contact method.

Photographs were taken using a Nikon D100 Camera in luminescence mode with settings; Focal length: $85 \mathrm{~mm}$, Shutter Speed: $4 \mathrm{~s}$ and Aperture: f/11.

\section{Investigations into development time}

When treating non-thermal papers, heat is used to speed up the reaction between the amino acids in the latent fingermark 15 and 1,2-indanedione. For thermal paper the application of heat to shorten development time is not feasible. Therefore the development time would be a compromise between quality of developed fingermarks and length of development period.

Latent fingermark quarters on unprinted and printed 20 thermal papers were developed using fluorous acidfree/IND/ $\mathbf{Z n C l}_{2}$-based treatment papers, with treatment times of either 24, 48, 72 or 96 hours (Figure 4).

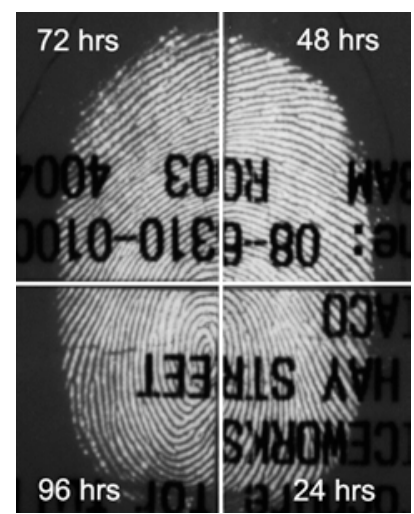

Fig.4 Latent fingermark on printed thermal paper where quarters were treated for different development times with fluorous acid-

free/IND/ $\mathrm{ZnCl}_{2}$ by the dry contact method. Photographs were taken using a Nikon D100 Camera in luminescence mode with settings; Focal length: $85 \mathrm{~mm}$, Shutter Speed: $2.5 \mathrm{~s}$ and Aperture: f/11.
30 On both unprinted and printed thermal papers, strong prints showed sufficient colour and luminescence after 24 hours with no noticeable increase in development at longer treatment times. However, weak fingermarks required longer development times, with sufficient development observed 35 after 48 hours.

While there was no noticeable increase in performance after 48 hours, samples observed after 78 days of development revealed fingermarks with significantly darker colour, more intense luminescence and ridge detail. While operationally, it 40 is not feasible to leave exhibits in treatment for 78 days, it can be concluded that leaving thermal paper exhibits in treatment for extended periods of time does not have an adverse effect.

\section{The dry contact method for non-thermal papers}

An investigation into the effectiveness of the 1,2-indanedione ${ }_{45}$ dry contact method for non-thermal papers compared to the AFP method for non-thermal papers (dipping the sample into the fluorous IND/ $\mathbf{Z n C l}_{2}$ working solution followed by heat treatment) was carried out. A solvent free method for the treatment of fingermarks on these surfaces would be ${ }_{50}$ beneficial particularly in cases where police are required to travel internationally with forensic equipment as the air transportation of hazardous materials is restricted. A dry reagent method would also be useful for samples that are fragile and have the potential to be damaged by standard ${ }_{55}$ development techniques.

Results of this preliminary experiment showed that for a depletion series of fingermarks on white photocopy paper the dry contact method using fluorous $\mathbf{I N D} / \mathbf{Z n C l}_{\mathbf{2}}$ treatment papers, with additional heating, developed fingermarks that 60 were visible in both absorbance and luminescence mode (Figure 5).
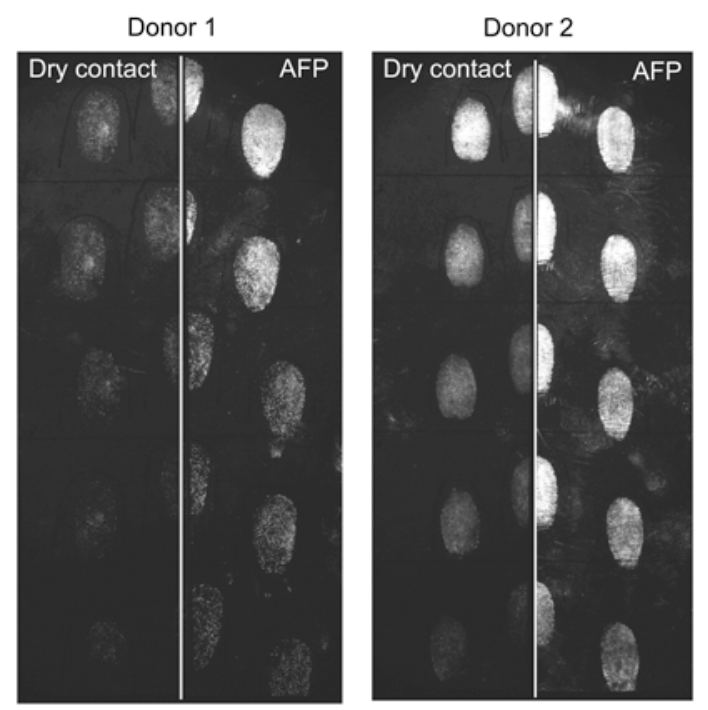

Fig.5 A depletion series from two donors on white photocopy paper, where halves were treated with fluorous $\mathrm{IND} / \mathrm{ZnCl}_{2}$ using the dry contact 65 method with additional heating or the AFP method for non-thermal papers (dipping and heat treatment). Photographs taken using a Nikon D300 Camera taken in luminescence mode with settings; Focal length: 60 $\mathrm{mm}$, Shutter Speed: $1 / 2.5 \mathrm{~s}$ and Aperture: $\mathrm{f} / 14$. A full size version of Fig.5 is available in the Electronic Supplementary Information. 
Halves treated with the AFP method (dipping, fluorous $\mathbf{I N D} / \mathbf{Z n C l}_{2}$, heat treatment) developed greater colour and luminescence than halves treated using the dry contact method. This is not unexpected as the fingermarks are 5 exposed to direct contact with a greater concentration of the development reagents in the wet dipping methods, than in the dry contact method. The reduced luminescence of samples treated using the adapted dry contact method may be due to the physical properties of the paper itself. Paper has a fibrous 10 surface, consisting of 'hills' and 'troughs', the uneven nature of the surface may limit the amount of contact between the sample and the treatment papers, thus reducing the methods ability to develop fingermarks. It should be noted that the dipping method results in noticeably higher background

15 luminescence compared to the dry contact method.

While the dry contact method could not develop fingermarks of equal luminescence and colour to the AFP method for non-thermal paper, it did develop fingermarks of reasonable quality when viewed in luminescence mode.

20

Comparison of the dry contact method to other development methods

A blind trial was used to compare the performance of the dry contact method with the standard method for thermal papers.

${ }_{25}$ Both the AFP thermal paper method (dipping in fluorous acid-free/IND/ $\mathbf{Z n C l}_{\mathbf{2}}$ working solution followed by air drying and no heat treatment) and the dry contact method (using fluorous acid-free/IND/ $\mathbf{Z n C l} \mathbf{~}_{\mathbf{2}}$ treatment papers) developed a similar proportion of fingermarks in luminescence and 30 absorbance mode. However, in absorbance mode it was easier to see fingermarks developed using the dry contact method as there was no discolouration of the background. This experiment showed that both the AFP method for thermal paper and dry contact method were equally effective in 35 developing latent fingermarks on thermal paper.

A direct comparison of the dry contact method with the AFP methods for non-thermal and thermal papers, and the 'Nin-dry' method was also performed using thermal paper (an example is shown in Figure 6). As expected, quarters treated 40 with the AFP method for normal paper (dipping in fluorous $\mathbf{I N D} / \mathbf{Z n C l}_{\mathbf{2}}$ working solution followed by heat treatment) showed blackening of the paper with no development (grade 0 ) of the latent fingermarks visible in absorbance mode, and weak to medium development (grades 1-2) in luminescence

45 mode. Quarters treated with the AFP method for thermal paper (dipping in fluorous acid-free/IND/ $\mathbf{Z} \mathbf{n C l}_{\mathbf{2}}$ working solution followed by air drying and no heat treatment) showed some discolouration of the background with the majority of latent fingermarks developing to grades 1 and 2 in absorbance

50 mode and grade 3 in luminescence mode. The dry contact method (using fluorous acid-free/IND/ $\mathbf{Z n C l}_{2}$ treatment papers) consistently developed fingermarks that were grade 3 in both absorbance and luminescence viewing modes. The 'Nin-dry' treated quarters were checked for development at 5524,48 and 72 hours, with the majority of samples showing grade 2 development in absorbance mode only after 72 hours of treatment. There was no visible luminescence from 'Nin- dry' treated quarters, as expected for a ninhydrin-based development. The development of quarters using the 'Nin${ }_{60}$ dry' method was compared to the 1,2-indanedione dry contact method at 24 hours, and it was observed that the 1,2indanedione dry contact method had developed all fingermarks to a better standard than the 'Nin-dry' method.
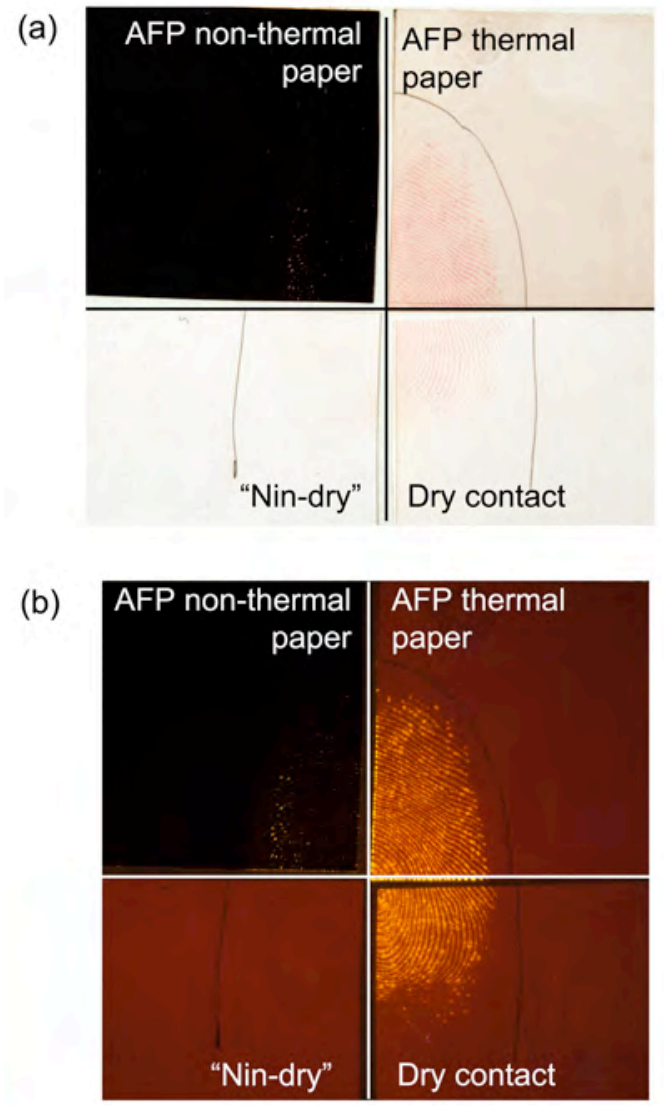

65 Fig.6 Latent fingermarks on unprinted thermal paper where quarters were treated using the AFP method for non-thermal paper (dipping in fluorous $\mathrm{IND} / \mathrm{ZnCl}_{2}$ working solution followed by heat treatment), the AFP method for thermal paper (dipping in fluorous acid-free/IND/ $\mathrm{ZnCl}_{2}$ working solution followed by air drying and no heat treatment), the 1,270 indanedione dry contact method (using fluorous acid-free/IND/ $/ \mathrm{ZnCl}_{2}$ treatment papers) or 'Nin-dry' (a ninhydrin-based dry contact method). Photographs taken with a Nikon D300 Camera in (a) absorbance mode with settings; Aperture: f/16 and Shutter Speed: 1/10 s and (b) luminescence mode with settings; Focal length: $60 \mathrm{~mm}$, Aperture: f/3.2 75 and Shutter Speed: $1 / 30 \mathrm{~s}$.

\section{Conclusions}

These studies indicate that the 1,2-indanedione dry contact method described here is a simple and reliable, nondestructive method for the development of latent fingermarks 80 on thermal paper. When compared to the 'Nin-dry' method, the 1,2-indanedione dry contact method developed fingermarks to a darker colour, that were also luminescent, in a shorter period of time. The dry contact method appears to be comparable to the current AFP recommended (dipping 85 without additional heat treatment) method for treating thermal paper with 1,2-indanedione (24 hours), without damaging the paper. 
This method shows promise for non-thermal documents that are fragile or for cases where international travel with forensic equipment is required. A larger scale operational trial in collaboration with a number of police fingerprint bureaux 5 throughout Australia is currently being planned. This will include investigations into the use of the 1,2-indanedione dry contact method with aged samples (older than one week).

\section{Acknowledgments}

The authors would like to thank Senior Constable Graham 10 Byard (Western Australia Police Forensic Division) for providing the 'Nin-dry' papers and treatment information, Prof Chris Lennard (University of Canberra), Renee Jelly and Lisa Swann (Curtin University of Technology) for helpful discussions during the course of this work and all the 15 fingermark donors. E.L.T.P is supported by an Australian Postgraduate Award. We also thank Curtin University of Technology for a Research and Teaching Fellowship (to D.H.B.).

\section{${ }_{20}$ Notes and references}

${ }^{a}$ Nanochemistry Research Institute, Department of Chemistry, Curtin University of Technology, GPO Box U1987, Perth, Western Australia 6845, Australia. Fax: +61 89266 2300; Tel: +61 89266 2484; E-mail: S.Lewis@curtin.edu.au.

$25 \dagger$ Electronic Supplementary Information (ESI) available: A full size version of Fig.5. See DOI: 10.1039/b000000x/

1. J. Almog, in Encyclopedia of Forensic Sciences, eds. J. Siegel, P. Saukko and G. Knupfer, Academic Press, Oxford, 2000.

30 2. S. K. Bramble, J. S. Brennan and A. S. Jay, in Encyclopedia of Forensic Sciences, Elsevier, Oxford, 2000, pp. 862-869.

3. A. R. W. Jackson and J. M. Jackson, Forensic Science, Pearson Prentice Hall, Harlow, England, 2004.

4. C. Champod, C. Lennard, P. Margot and M. Stoilovic, in Fingerprints and Other Ridge Skin Impressions, CRC Press, 2004.

5. R. Jelly, E. L. T. Patton, C. Lennard, S. W. Lewis and K. F. Lim, Analytica Chimica Acta, 2009, 652, 128-142.

6. J. Almog, A. Klein, I. Davidi, Y. Cohen, M. Azoury and M. LevinElad, J. Forensic Sci., 2008, 53, 364-368.

40 7. J. T. Stimac, J. Forensic Ident., 2003, 53, 185 - 197.

8. C. Wallace-Kunkel, C. Lennard, M. Stoilovic and C. Roux, Forensic Sci. Int., 2007, 168, 14-26.

9. L. Schwarz and I. Klenke, J. Forensic Sci., 2007, 52, 649-655.

10. M. Rongliang and W. Qun, J. Forensic Ident., 2006, 56, 364 - 373.

45 11. BVDA, Product Information for ThermaNin, http://www.bvda.com/EN/prdctinf/en_thermanin.html, Accessed 26 November, 2008.

12. S. D. Siegel, J. Forensic Ident., 2007, 57, 240 - 243.

13. L. Schwarz, P. Nat and I. Frerichs, J. Forensic Sci., 2002, 47, 12741277.

14. J. Brennan, S. Bramble, S. Crabtree and G. Wright, J. Forensic Ident., 1995, 45, 373 - 380.

15. O. P. Jasuja and G. Singh, Forensic Sci. Int., 2009, 192, e1-e16.

16. B. Broniek and W. Knaap, J. Forensic Ident., 2002, 52, 427 - 432.

55 17. S. G. V. Kusenthiran, T. Rogers and W. Knaap, J. Forensic Ident., 2010, 60, 34-44

18. M. Wakefield and S. Armitage, J. Forensic Ident., 2005, 55, 202 213.

19. J. L. Lee, S. M. Bleay, V. G. Sears, S. Mehmet and R. Croxton, J. 60 Forensic Ident., 2009, 59, 545-568.

20. H. Marquez, J. Forensic Ident., 1999, 49, 122 - 123.

21. P. McMahon, The Print, 1998, 14, 4 -5.
22. J. T. Stimac, J. Forensic Ident., 2003, 53, 265-271.

23. M. Stoilovic and C. Lennard, AFP Workshop Manual: Fingerprint ${ }_{65}$ Detection \& Enhancement, Forensic Services, Australian Federal Police, Canberra, 2006.

24. H. Bandey, Fingerprint Development and Imaging Newsletter: Special Edition, 2004, http://scienceandresearch.homeoffice.gov.uk/hosdb/publications/fing

70 erprint-publications/FingerprintNewsFeb08062835.pdf?view=Binary, Accessed 25 March, 2009.

25. S. Wiesner, E. Springer, Y. Sasson and J. Almog, J. Forensic Sci., 2001, 46, 1082-1084. 